\title{
Aplicação foliar de fungicidas e incidência de grãos ardidos e fumonisinas totais em milho
}

\author{
Fabrício Eustáquio Lanza(1), Laércio Zambolim(1), Rodrigo Veras da Costa(2), Dagma Dionísia da Silva(2), \\ Valéria Aparecida Vieira Queiroz ${ }^{(2)}$, Douglas Ferreira Parreira ${ }^{(1)}$, Simone Martins Mendes $^{(2)}$, \\ André Gomes Coelho Souza(1) e Luciano Viana Cota(2)
}

\begin{abstract}
(1)Universidade Federal de Viçosa, Departamento de Fitopatologia, Avenida Peter Henry Rolfs, s/no, Campus Universitário, CEP $36570-000$ Viçosa, MG, Brasil. E-mail: falanza@bol.com.br, zambolim@ufv.br, douglas2002ufv@yahoo.com.br, agcsouza@yahoo.com.br (2)Embrapa Milho e Sorgo, Rodovia MG-424, Km 45, CEP 35701-970 Sete Lagoas, MG, Brasil. E-mail: rodrigo.veras@embrapa.br, dagma.silva@embrapa.br, valeria.vieira@embrapa.br, simone.mendes@embrapa.br, luciano.cota@embrapa.br
\end{abstract}

Resumo - O objetivo deste trabalho foi avaliar a eficiência da aplicação foliar de fungicidas na redução da incidência de patógenos fúngicos, de grãos ardidos e de fumonisinas totais em grãos de milho (Zea mays). Foram conduzidos três ensaios: um no município de Luís Eduardo Magalhães, na Bahia, e dois em Sete Lagoas, em Minas Gerais, nas safras 2010/2011 e 2011/2012, com cultivo de diferentes híbridos comerciais. Os seguintes fungicidas foram aplicados zero, uma e duas vezes: picoxistrobina + ciproconazol, piraclostrobina + epoxiconazole, trifloxistrobina + tebuconazole, azoxistrobina + ciproconazol e tiofanato metílico. Em todos os ensaios, foram realizados a quantificação da incidência de grãos ardidos, o teste de patologia de sementes e a quantificação dos teores de fumonisinas totais. Não foi observada diferença significativa para os fatores fungicida e número de aplicações, exceto para rendimento de grãos, em todos os ensaios. Esses resultados são indicativos da ineficiência da aplicação de fungicidas na redução da incidência de patógenos fúngicos, de grãos ardidos e dos teores de fumonisinas totais em grãos de milho.

Termos para indexação: Fusarium, Zea mays, controle químico, micotoxinas, patógenos fúngicos.

\section{Fungicide leaf application and incidence of kernel rot and total fumonisins in corn}

\begin{abstract}
The objective of this work was to evaluate fungicide leaf application on the reduction of fungal pathogen incidence, kernel rot, and total fumonisins in corn (Zea mays) kernels. Three experiments were performed: one in the municipality of Luís Eduardo Magalhães, in the state of Bahia, and two in the municipality of Sete Lagoas, in the state of Minas Gerais, Brazil, during the 2010/2011 and 2011/2012 crop seasons, with planting of different commercial hybrids. The following fungicides were applied zero, one, and two times: picoxystrobin + cyproconazole, pyraclostrobin + epoxiconazole, trifloxystrobin + tebuconazole, azoxystrobin + cyproconazole, and thiophanate-methyl. For all trials, the quantification of kernel rot incidence, the grain pathology test, and the quantification of total fumonisins were performed. No significant difference was observed for the factors fungicide and number of applications, except for grain yield, in all trials. These results show the ineffectiveness of fungicide applications in reducing fungi incidence, kernel rot, and levels of total fumonisins in corn kernels.
\end{abstract}

Index terms: Fusarium, Zea mays, chemical control, mycotoxins, pathogenic fungi.

\section{Introdução}

Na safra 2014/2015, o Brasil produziu cerca de 84 milhões de toneladas de milho (Zea mays L.), o que o tornou, além de autossuficiente para o consumo interno, um dos principais países exportadores desse cereal. Classificado como o terceiro maior exportador mundial, o Brasil comercializa quantidades superiores a 27 milhões de toneladas para países como o Irã, a Colômbia e a Coreia do Sul (Agrianual..., 2015).
Contudo, as exigências comerciais relacionadas à qualidade dos grãos, destinados tanto à exportação quanto ao consumo interno, têm se tornado cada vez mais rígidas, principalmente em relação à qualidade sanitária dos grãos e à presença de micotoxinas (Agência Nacional de Vigilância Sanitária, 2011).

No Brasil, o milho, uma cultura amplamente cultivada sob diversas condições climáticas, está sujeito ao ataque de vários patógenos que afetam as espigas, o que causa podridões que resultam na redução 
da qualidade dos grãos e no aumento do acúmulo de micotoxinas; problemas que geram graves ameaças fitossanitárias para a cultura no País (Oliveira et al., 2004; Pereira et al., 2005).

$\mathrm{O}$ fungo Fusarium verticillioides (Saccardo) Nirenberg é considerado o principal patógeno causador de podridões de espigas em milho e pode causar tanto infecções sintomáticas, como a de grãos ardidos, quanto assintomáticas. Além de ser encontrado em maior frequência nos grãos, $F$. verticillioides é a espécie que apresenta maior capacidade de produção de fumonisinas. As fumonisinas, tóxicas a animais e associadas a alguns tipos de câncer em seres humanos, são consideradas as principais micotoxinas em grãos de milho (Gelderblom et al., 1988; Munkvold \& Desjardins, 1997; Jackson \& Jablonski, 2004). O Ministério da Agricultura, Pecuária e Abastecimento, junto com a Agência Nacional de Vigilância Sanitária, estabeleceu o limite máximo de $5,0 \mu \mathrm{g} \mathrm{g}^{-1}$ para fumonisinas em grãos de milho (Agência Nacional de Vigilância Sanitária, 2011).

Tradicionalmente, o manejo das doenças na cultura do milho era realizado, principalmente, por meio da utilização de cultivares resistentes, associadas às medidas culturais. No entanto, a partir da severa epidemia de cercosporiose (Cercospora zeae-maydis), que ocorreu na região Sudoeste do estado de Goiás em 2000, houve aumento acentuado do uso de fungicidas em lavouras comerciais destinadas à produção de grãos (Costa et al., 2012). Assim, apesar da resistência genética ser uma das principais estratégias de manejo de doenças em milho, na atualidade, o controle químico se apresenta como uma das medidas mais utilizadas pelos produtores. Em muitos casos, essa é a única medida eficiente e economicamente viável de garantir altas produtividades e qualidade de produção (Kimati, 2011; Costa et al., 2012).

Entretanto, há dúvidas sobre a efetividade dessa medida para o controle de podridões de espigas e grãos ardidos em milho (Oliveira et al., 2004; Pereira et al., 2005). Alguns trabalhos apontam a eficiência de fungicidas do grupo das estrobilurinas, em mistura com trazóis, na redução de grãos ardidos (Juliatti et al., 2007; Duarte et al., 2009; De Curtis et al., 2011; Brito et al., 2012); mas, também, há relatos de ausência ou baixa eficiência no controle dessas enfermidades com a aplicação de fungicidas (Mazzoni et al., 2011; Small et al., 2012). Essas variações nos resultados obtidos estão relacionadas aos diferentes fungicidas disponíveis, quanto ao número de aplicações e às diferentes cultivares utilizadas. Esses resultados, portanto, são indicativos da grande inconsistência na eficiência desse método de controle sobre a incidência de grãos ardidos em milho.

O objetivo deste trabalho foi avaliar a eficiência da aplicação foliar de fungicidas na redução da incidência de patógenos fúngicos, de grãos ardidos e de fumonisinas totais em grãos de milho (Zea mays).

\section{Material e Métodos}

Foram conduzidos três ensaios, um no município de Luís Eduardo Magalhães, na Bahia, e dois em Sete Lagoas, em Minas Gerais, nas safras 2010/2011 e 2011/2012.

O experimento em Luís Eduardo Magalhães foi conduzido em delineamento experimental de blocos ao acaso, em arranjo fatorial $4 \times 3$ (fungicidas $\mathrm{x}$ número de aplicações), com três repetições. Os fungicidas corresponderam às seguintes misturas comerciais registradas para uso na cultura do milho: picoxistrobina + ciproconazol $\left(0,30+0,60 \mathrm{~L} \mathrm{ha}^{-1}\right)$, piraclostrobina + epoxiconazole $\left(0,75+0,50 \mathrm{~L} \mathrm{ha}^{-1}\right)$, trifloxistrobina + tebuconazole $\left(0,60+0,60 \mathrm{~L} \mathrm{ha}^{-1}\right) \mathrm{e}$ azoxistrobina + ciproconazol $\left(0,30+0,60 \mathrm{~L} \mathrm{ha}^{-1}\right)$. Já o número de aplicações consistiram em: sem aplicação; uma aplicação na fase de dez folhas definitivas (V10); e duas aplicações em V10 e 15 dias após a primeira.

O híbrido utilizado foi o 30F53, semeado em $10 / 11 / 2010$. As parcelas foram constituídas por quatro linhas de 5,0 m, com espaçamento de $0,8 \mathrm{~m}$ entre linhas e média de cinco plantas por metro linear. Foi mantida uma distância de 1,0 m entre as laterais e as extremidades de cada parcela. A adubação de plantio consistiu na aplicação de $350 \mathrm{~kg} \mathrm{ha}^{-1}$ da formulação 8-28-16 (NPK) + Zn, e de adubações de cobertura aplicadas aos 30 e 45 dias após o plantio, tendo-se utilizado $150 \mathrm{~kg} \mathrm{ha}^{-1}$ de ureia $\left(\mathrm{CH}_{4} \mathrm{~N}_{2} \mathrm{O}\right)$.

Em todas as pulverizações, foi adicionado óleo mineral parafínico na proporção de $0,5 \%$ do volume de calda de fungicida. As aplicações foram realizadas com auxílio de pulverizador costal pressurizado por $\mathrm{CO}_{2}$, com pressão de 4,0 bar e vazão constante de 300 $\mathrm{L} \mathrm{ha}^{-1}$. Durante a aplicação da calda de fungicida, a barra de pulverização foi mantida a uma altura média de $50 \mathrm{~cm}$ acima da parte superior das plantas. 
Já o experimento realizado em Sete Lagoas, na safra 2010/2011, foi conduzido na área experimental da Embrapa Milho e Sorgo. Utilizou-se o delineamento experimental utilizado de blocos ao acaso em arranjo fatorial $3 \times 7$ (fungicidas $\mathrm{x}$ número de aplicações), com três repetições. Os tratamentos estão apresentados na Tabela 1.

A cultivar BRS 1035 foi semeada em 17/11/2010, tendo-se utilizado metodologia, espaçamento, adubação e preparo de caldas iguais aos descritos para o ensaio instalado em Luís Eduardo Magalhães.

O segundo experimento realizado em Sete Lagoas, na safra 2011/2012, também foi conduzido na área experimental da Embrapa Milho e Sorgo. Utilizouse o delineamento experimental utilizado de blocos ao acaso em arranjo fatorial $4 \times 2$ (híbridos x número de aplicações), com três repetições. Foram utilizados os híbridos 30F35, DKB 330, DKB 390 e DKB 550, semeados em 20/11/2011. Os espaçamentos, adubação e preparo da calda seguiram a mesma metodologia descrita para o primeiro experimento. $\mathrm{O}$ fungicida utilizado foi o tiofanato metílico, aplicado zero, uma
(V10) e duas (V10 e VT) vezes, na proporção de $1,0 \mathrm{~L} \mathrm{ha}^{-1}$.

Ao final do ciclo da cultura, em todos os ensaios, foi realizada a colheita manual de todas as espigas das duas linhas centrais de cada parcela. Após a colheita, as espigas foram debulhadas, e a massa de grãos, de cada parcela, foi homogeneizada. A umidade da massa de grãos foi determinada com auxílio de medidor de umidade portátil, modelo mini Gac plus (Dickey-john, Corn Belt Testing, Inc., Minneapolis, MN, EUA), com resolução de $0,1 \%$ de umidade. Após a homogeneização, foram coletadas duas amostras de $500 \mathrm{~g}$ de cada parcela. As amostras foram encaminhadas para análise da incidência de grãos ardidos, da incidência de fungos fitopatogênicos associados aos grãos, das fumonisinas totais e do rendimento de grãos.

A incidência de grãos ardidos foi obtida por meio da separação visual dos grãos assintomáticos daqueles sintomáticos (ardidos). Foram considerados como ardidos os grãos que apresentavam pelo menos $25 \%$ de sua superfície com descolorações, cujo matiz pode variar de marrom-claro a roxo ou de vermelho-claro a vermelho-intenso (Pinto, 2005). Os grãos ardidos foram

Tabela 1. Fungicidas, épocas e estádios em que foram aplicados na cultura do milho (Zea mays), no ensaio conduzido em Sete Lagoas, MG, na safra 2011/2012.

\begin{tabular}{|c|c|c|c|c|}
\hline \multirow[t]{2}{*}{ Identificação } & \multirow[t]{2}{*}{ Fungicidas } & \multicolumn{3}{|c|}{ Estádio da cultura do milho } \\
\hline & & Primeira aplicação & Segunda aplicação & Terceira aplicação \\
\hline$\overline{1}$ & Azoxistrobina + Ciproconazol & - & - & - \\
\hline 2 & Azoxistrobina + Ciproconazol & V6 a V8 $8^{(1)}$ & - & - \\
\hline 3 & Azoxistrobina + Ciproconazol & V6 a V8 & 15 dias após a primeira & - \\
\hline 4 & Azoxistrobina + Ciproconazol & V6 a V8 & 15 dias após a primeira & 15 dias após a segunda \\
\hline 5 & Azoxistrobina + Ciproconazol & - & 15 dias após a primeira & - \\
\hline 6 & Azoxistrobina + Ciproconazol & - & 15 dias após a primeira & 15 dias após a segunda \\
\hline 7 & Azoxistrobina + Ciproconazol & - & - & 15 dias após a segunda \\
\hline 8 & Piraclostrobina + Epoxiconazole & - & - & - \\
\hline 9 & Piraclostrobina + Epoxiconazole & V6 a V8 & - & - \\
\hline 10 & Piraclostrobina + Epoxiconazole & V6 a V8 & 15 dias após a primeira & - \\
\hline 11 & Piraclostrobina + Epoxiconazole & V6 a V8 & 15 dias após a primeira & 15 dias após a segunda \\
\hline 12 & Piraclostrobina + Epoxiconazole & - & 15 dias após a primeira & - \\
\hline 13 & Piraclostrobina + Epoxiconazole & - & 15 dias após a primeira & 15 dias após a segunda \\
\hline 14 & Piraclostrobina + Epoxiconazole & - & - & 15 dias após a segunda \\
\hline 15 & Trifloxistrobina + Tebuconazole & - & - & - \\
\hline 16 & Trifloxistrobina + Tebuconazole & V6 a V8 & - & - \\
\hline 17 & Trifloxistrobina + Tebuconazole & V6 a V8 & 15 dias após a primeira & - \\
\hline 18 & Trifloxistrobina + Tebuconazole & V6 a V8 & 15 dias após a primeira & 15 dias após a segunda \\
\hline 19 & Trifloxistrobina + Tebuconazole & - & 15 dias após a primeira & - \\
\hline 20 & Trifloxistrobina + Tebuconazole & - & 15 dias após a primeira & 15 dias após a segunda \\
\hline 21 & Trifloxistrobina + Tebuconazole & - & - & 15 dias após a segunda \\
\hline
\end{tabular}

${ }^{(1)}$ V6 a V8, estádio de desenvolvimento de plantas de milho com seis a oito folhas, respectivamente. -, não houve aplicação de fungicida. 
pesados, e os dados foram expressos em percentagem do peso total da amostra.

Para determinar a incidência dos fungos, utilizou-se o método de incubação em substrato de papel-filtro com congelamento, denominado "blotter test" (Machado, 1988). Os grãos de cada tratamento foram separados em ardidos e assintomáticos, e, de cada parte, foram avaliados 100 grãos em quatro repetições de 25 . Estes grãos foram previamente desinfestados em hipoclorito de sódio a $2 \%$, por $5 \mathrm{~min}$, e distribuídos em caixas tipo "gerbox", contendo três folhas de papel-filtro umedecidas com ágar-água $5 \%$ e esterilizadas a $121^{\circ} \mathrm{C}$, por $30 \mathrm{~min}$. As caixas foram mantidas em sala à temperatura ambiente, sob luz contínua durante 24 horas, para estimular a germinação. Posteriormente, as caixas contendo os grãos foram transferidas para freezer a $-20^{\circ} \mathrm{C}$, por 24 horas, para inibir a germinação e evitar a contaminação de grão a grão. Em seguida, esse material foi mantido em BOD a $25^{\circ} \mathrm{C}$ e fotoperíodo de 12 horas, por 10 dias, para estimular o crescimento dos fungos. Ao final desse período, os grãos foram examinados individualmente, e os fungos fitopatogênicos associados aos grãos ardidos e assintomáticos, quando presentes, foram identificados e quantificados separadamente, com auxílio de microscópio estereoscópico.

Para a quantificação dos teores de fumonisinas totais foi realizada a homogeneização do teor de água das amostras de $500 \mathrm{~g}$, que foram colocadas em estufa de ventilação forçada, a $65^{\circ} \mathrm{C}$, por 72 horas. Após o resfriamento, as amostras foram trituradas em moinho tipo Willey e peneiradas em peneira de 20 mesh. A amostra moída foi novamente homogeneizada, tendose coletado uma subamostra de $10 \mathrm{~g}$. Desta subamostra, foram extraídas, com uso de solução de metanol:água $(80: 20)$, as fumonisinas totais, posteriormente purificadas em colunas de imunoafinidade FumoniTest (Vicam, a Water Business, Milford, MA, USA), de acordo com o manual do fabricante. Todos os extratos obtidos foram imediatamente utilizados para a quantificação de fumonisinas totais, em fluorímetro série 4 EX (Vicam, a Water Business, Milford, MA, USA) (Ramos et al., 2010b).

Todas as amostras foram analisadas em duplicatas. Uma amostra de referência (TR-F100, Trilogy Analytical Laboratory, Inc., Washington, MO, EUA) com $4,1 \pm 0,5 \mu \mathrm{g} \mathrm{g}^{-1}$ de fumonisinas totais, quantificada por equipamento cromatografia líquida de alta eficiência, foi utilizada para o teste de acurácia do método de colunas de imunoafinidade.

O rendimento de grãos foi determinado de acordo com a metodologia descrita pelas Regras para Análise de Sementes (Brasil, 2009) e compreendeu a separação e a pesagem de mil grãos obtidos de cada tratamento. Essa variável foi utilizada para verificar o efeito da aplicação dos fungicidas no peso dos grãos, uma vez que se correlaciona com a produtividade.

Os dados referentes à incidência de grãos ardidos, à incidência de fungos nos grãos, aos teores de fumonisinas totais e ao rendimento de grãos, após transformados em arco seno $(\mathrm{x} / 100)^{0,5}$, foram submetidos à análise de variância (Anova). Quando detectada diferença significativa pelo teste $\mathrm{F}$, as médias foram comparadas pelo teste de Tukey, a 5\% de probabilidade, com auxílio do programa Sisvar (Universidade Federal de Lavras, Lavras, MG). Para a apresentação dos resultados, foram utilizados os dados sem transformação.

\section{Resultados e Discussão}

A aplicação foliar de fungicidas, independentemente do número e da época de aplicações, não foi eficiente em reduzir a incidência de grãos ardidos em milho (Tabelas 2, 3, 4 e 5). Nos dois primeiros ensaios, a variável incidência de grãos ardidos não apresentou diferença quanto aos fatores fungicidas e número de aplicações, nem quanto à interação fungicidas $\mathrm{x}$ número de aplicações (Tabela 2). A incidência média de grãos ardidos foi de 7,3 e 4,8\% para os ensaios em Luís Eduardo Magalhães e Sete Lagoas, na safra 2010/2011, respectivamente.

A aplicação do fungicida tiofanato metílico, utilizado em Sete Lagoas, na safra 2011/2012, também não resultou em diferença para peso de grãos ardidos. Porém, os genótipos utilizados diferiram entre si quando analisado o peso de grãos ardidos. O híbrido $30 \mathrm{~F} 35$ apresentou a menor percentagem de grãos ardidos $(0,7 \%)$, enquanto o DKB 550 foi o mais suscetível, tendo apresentado média de 17,4\% (Tabela 3).

Assim, houve ausência de efeito da aplicação de fungicidas na redução da incidência de grãos ardidos nos três ensaios realizados, apesar das distintas condições meteorológicas e dos diferentes híbridos e fungicidas utilizados. Esse resultado corrobora os obtidos por Mazzoni et al. (2011) e Small et al. (2012). 
Segundo esses autores, a aplicação foliar de diferentes fungicidas do grupo das estrobilurinas, em mistura com triazóis, não reduz a incidência de grãos ardidos. Contudo, Juliatti et al. (2007) relataram a eficiência dos fungicidas piraclostrobina + epoxiconazole, em duas aplicações, na redução da incidência de grãos ardidos, embora também tenham observado a ineficiência dos fungicidas azoxistrobina, hidróxido de cobre e azoxistrobina + ciproconazol, no controle de patógenos fúngicos presentes nos grãos. Ao contrário de Juliatti et al. (2007), Duarte et al. (2009) constataram eficiência na redução da incidência de grãos ardidos, quando aplicado o fungicida azoxistrobina + ciproconazol. Esses resultados são indicativos de que ainda há inconsistências quanto à eficiência da utilização de fungicidas na redução de grãos ardidos em milho.

Em todos os ensaios, foram detectados quatro gêneros de fungos associados aos grãos: Fusarium spp., Penicillium sp., Stenocarpella sp. e Aspergillus sp. Houve diferença para o fator tipo de grão, ou seja, ardido ou assintomático (Tabela 2). Entretanto, os fatores híbrido, fungicida, número de aplicações e a interação entre estes não diferiram entre si.

Apesar da diferença observada quanto ao tipo de grãos, a incidência de Fusarium sp. foi elevada tanto nos grãos sintomáticos (ardidos) quanto nos assintomáticos. As maiores incidências de Fusarium sp. foram detectadas em grãos ardidos, em

Tabela 2. Análise de variância (Anova) para os fatores fungicidas (F), número de aplicações (NA), tipo de grão (TG), ardido ou assintomático, e híbrido de milho $(\mathrm{H})$, para as variáveis peso de mil grãos, peso de grãos ardidos (PGA), incidência de Fusarium sp., Penicillium sp. e Stenocarpella sp., e teores de fumonisinas totais em grãos de milho (Zea mays), em um ensaio conduzido no município de Luís Eduardo Magalhães, BA, e dois em Sete Lagoas, MG.

\begin{tabular}{|c|c|c|c|c|c|c|c|c|c|}
\hline \multirow[t]{2}{*}{ Variáveis } & \multicolumn{3}{|c|}{ Luís Eduardo Magalhães, safra 2010/2011 } & \multicolumn{3}{|c|}{ Sete Lagoas, safra 2010/2011 } & \multicolumn{3}{|c|}{ Sete Lagoas, safra 2011/2012 } \\
\hline & Fator & Valor de $\mathrm{p}$ & $\mathrm{CV}(\%)$ & Fator & Valor de $\mathrm{p}$ & $\mathrm{CV}(\%)$ & Fator & Valor de $\mathrm{p}$ & $\mathrm{CV}(\%)$ \\
\hline \multirow{3}{*}{ Peso de mil grãos } & $\mathrm{F}$ & $<0,05$ & \multirow{3}{*}{10,9} & $\mathrm{~F}$ & ns & \multirow{3}{*}{8,4} & $\mathrm{H}$ & $<0,01$ & \multirow{3}{*}{9,2} \\
\hline & NA & $<0,05$ & & NA & ns & & NA & $<0,01$ & \\
\hline & $\mathrm{F} \times \mathrm{NA}$ & ns & & $\mathrm{F} \times \mathrm{NA}$ & ns & & $\mathrm{H} \times \mathrm{NA}$ & ns & \\
\hline \multirow{3}{*}{ PGA } & $\mathrm{F}$ & ns & \multirow{3}{*}{34,6} & $\mathrm{~F}$ & $\mathrm{~ns}$ & \multirow{3}{*}{32,4} & $\mathrm{H}$ & $<0,01$ & \multirow{3}{*}{71,0} \\
\hline & NA & ns & & NA & ns & & NA & ns & \\
\hline & $\mathrm{F} \times \mathrm{NA}$ & ns & & $\mathrm{F} \times \mathrm{NA}$ & $\mathrm{ns}$ & & $\mathrm{H} \times \mathrm{NA}$ & ns & \\
\hline \multirow{7}{*}{ Fusarium sp. } & $\mathrm{F}$ & $\mathrm{ns}$ & \multirow{7}{*}{26,6} & $\mathrm{~F}$ & ns & \multirow{7}{*}{22,2} & $\mathrm{H}$ & ns & \multirow{7}{*}{15,1} \\
\hline & NA & ns & & NA & ns & & NA & ns & \\
\hline & TG & $<0,01$ & & $\mathrm{TG}$ & $<0,01$ & & $\mathrm{TG}$ & $<0,01$ & \\
\hline & $\mathrm{F} \times \mathrm{NA}$ & ns & & F x NA & ns & & $\mathrm{H} \times \mathrm{NA}$ & $\mathrm{ns}$ & \\
\hline & $\mathrm{F} \times \mathrm{TG}$ & ns & & $\mathrm{F} \times \mathrm{TG}$ & ns & & $\mathrm{H}$ x TG & ns & \\
\hline & TG $x$ NA & ns & & TG $x$ NA & ns & & TG $x$ NA & ns & \\
\hline & $\mathrm{F} \times \mathrm{NA} \times \mathrm{TG}$ & ns & & $\mathrm{F} \times \mathrm{NA} \times \mathrm{TG}$ & ns & & $\mathrm{H} \times \mathrm{NA} \times \mathrm{TG}$ & ns & \\
\hline \multirow{7}{*}{ Penicillium sp. } & $\mathrm{F}$ & $\mathrm{ns}$ & \multirow{7}{*}{31,6} & $\mathrm{~F}$ & $\mathrm{~ns}$ & \multirow{7}{*}{39,7} & $\mathrm{H}$ & $\mathrm{ns}$ & \multirow{7}{*}{37,9} \\
\hline & NA & ns & & NA & $\mathrm{ns}$ & & NA & ns & \\
\hline & $\mathrm{TG}$ & $<0,01$ & & TG & $<0,01$ & & $\mathrm{TG}$ & $<0,01$ & \\
\hline & $\mathrm{F} \times \mathrm{NA}$ & ns & & $\mathrm{F} \times \mathrm{NA}$ & ns & & $\mathrm{H} \times \mathrm{NA}$ & ns & \\
\hline & $\mathrm{F} \times \mathrm{TG}$ & ns & & $\mathrm{F} \times \mathrm{TG}$ & ns & & $\mathrm{H} \times \mathrm{TG}$ & ns & \\
\hline & TG $x$ NA & ns & & TG $x$ NA & ns & & TG $x$ NA & ns & \\
\hline & $\mathrm{F} \times \mathrm{NA} \times \mathrm{TG}$ & ns & & F x NA x TG & ns & & $\mathrm{H} \times \mathrm{NA} \times \mathrm{TG}$ & ns & \\
\hline \multirow{7}{*}{ Stenocarpella sp. } & $\mathrm{F}$ & $\mathrm{ns}$ & \multirow{7}{*}{51,4} & $\mathrm{~F}$ & ns & \multirow{7}{*}{62,4} & $\mathrm{H}$ & $\mathrm{ns}$ & \multirow{7}{*}{57,6} \\
\hline & NA & ns & & NA & $\mathrm{ns}$ & & NA & ns & \\
\hline & TG & $<0,05$ & & TG & $<0,05$ & & $\mathrm{TG}$ & $<0,05$ & \\
\hline & $\mathrm{F} \times \mathrm{NA}$ & ns & & $\mathrm{F} \times \mathrm{NA}$ & $\mathrm{ns}$ & & $\mathrm{H} \times \mathrm{NA}$ & ns & \\
\hline & $\mathrm{F} \times \mathrm{TG}$ & ns & & $\mathrm{F} \times \mathrm{TG}$ & ns & & $\mathrm{H} \times \mathrm{TG}$ & ns & \\
\hline & TG $x$ NA & ns & & TG $x$ NA & ns & & TG $x$ NA & ns & \\
\hline & $\mathrm{F} \times \mathrm{NA} \times \mathrm{TG}$ & ns & & $\mathrm{F} \times \mathrm{NA} \times \mathrm{TG}$ & ns & & $\mathrm{H} \times \mathrm{NA} \times \mathrm{TG}$ & ns & \\
\hline \multirow{3}{*}{ Fumonisinas totais } & $\mathrm{F}$ & ns & \multirow{3}{*}{31,7} & $\mathrm{~F}$ & $\mathrm{~ns}$ & \multirow{3}{*}{25,6} & $\mathrm{H}$ & $<0,01$ & \multirow{3}{*}{33,6} \\
\hline & NA & ns & & NA & ns & & NA & ns & \\
\hline & F x NA & ns & & F x NA x TG & ns & & $\mathrm{H} \times \mathrm{NA}$ & ns & \\
\hline
\end{tabular}

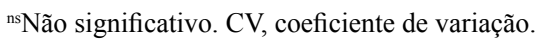


todos os ensaios, quando comparadas às incidências em grãos assintomáticos, respectivamente, nos ensaios em Luís Eduardo Magalhães e em Sete Lagoas, nas safras 2010/2011 e 2011/2012 (Tabela 4).

Para Penicillium sp., foram observados maiores valores de incidência nos grãos assintomáticos, em todos os ensaios, em comparação aos grãos ardidos. Já a incidência de Stenocarpella sp. foi predominante em grãos ardidos; praticamente não foi detectada a presença desse gênero nos grãos visualmente sadios.

Não houve diferença, em ambos os ensaios em Sete Lagoas, para os dados de incidência de Aspergillus sp. Para este gênero, os valores médios de incidência foram de 3,6, 0,2 e 0,1\%, respectivamente, para os ensaios em Luís Eduardo Magalhães e em Sete Lagoas, nas safras 2010/2011 e 2011/2012.

Esses resultados são indicativos de que a aplicação foliar de fungicidas não apresentou eficiência na redução da incidência de patógenos fúngicos nos grãos

Tabela 3. Rendimento de grãos (peso de mil grãos), peso de grãos ardidos (PGA) e fumonisinas totais (FT) para os fatores híbridos e número de aplicações de tiofanato metílico, no ensaio conduzido em Sete Lagoas, MG, na safra $2011 / 2012^{(1)}$.

\begin{tabular}{lccc}
\hline Híbrido & $\begin{array}{c}\text { Rendimento } \\
\text { de grãos }(\mathrm{g})\end{array}$ & $\begin{array}{c}\text { PGA } \\
(\%)\end{array}$ & $\begin{array}{c}\text { FT } \\
(\mathrm{ppm})\end{array}$ \\
\hline DKB 330 & $204,1 \mathrm{a}$ & $4,2 \mathrm{ab}$ & $3,4 \mathrm{~b}$ \\
30 F35 & $227,8 \mathrm{ab}$ & $0,72 \mathrm{a}$ & $2,1 \mathrm{a}$ \\
DKB 550 & $245,8 \mathrm{bc}$ & $17,4 \mathrm{~b}$ & $2,0 \mathrm{ab}$ \\
DKB 390 & $254,6 \mathrm{c}$ & $10,2 \mathrm{ab}$ & $2,0 \mathrm{a}$ \\
\hline Número de aplicações & & & \\
0 & $216,8 \mathrm{a}$ & $\mathrm{ns}$ & $\mathrm{ns}$ \\
1 & $223,7 \mathrm{a}$ & $\mathrm{ns}$ & $\mathrm{ns}$ \\
2 & $249,4 \mathrm{~b}$ & $\mathrm{~ns}$ & $\mathrm{~ns}$ \\
\hline
\end{tabular}

${ }^{(1)}$ Médias seguidas de letras iguais não diferem pelo teste de Scott-Knott,

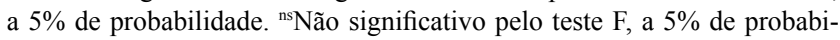
lidade. e que a aplicação foliar de fungicidas não resultou em controle da incidência de fungos em alguns genótipos de milho. Os resultados obtidos por Duarte et al. (2009) confirmam parcialmente os do presente trabalho.

A detecção dos fungos Fusarium sp., Stenocarpella sp., Penicillium sp. e Aspergillus sp. também está de acordo com relatos que descrevem estes fungos como sendo os principais microrganismos associados aos grãos de milho no Brasil (Pinto, 2001, 2005; Ramos et al., 2010a). Contudo, no presente trabalho, houve maior incidência de Fusarium sp. e Stenocarpella sp. associada a grãos ardidos. Resultados semelhantes foram encontrados por Munkvold \& Desjardins (1997), que relataram Fusarium spp. como o fungo mais encontrado associado aos grãos, principalmente aos ardidos. Porém, esses mesmos autores relataram que esses fungos também podem ocorrer em alta frequência em grãos assintomáticos, como observado no presente trabalho. Já segundo Casa et al. (2006), Stenocarpella sp. está principalmente associada a grãos ardidos e pode ser o principal agente de podridão de grãos na cultura do milho. Pinto (2005) e Ramos et al. (2010a) também verificaram que a elevada incidência de Fusarium sp. e Stenocarpella sp. está diretamente relacionada à maior incidência de grãos ardidos. Estes autores ainda apontaram que outros fungos também podem ser observados em frequência elevada, como Penicillium spp. e Aspergillus spp.; no entanto, estes patógenos causam maiores danos em grãos armazenados. Embora, de acordo com o presente trabalho, a maior prevalência de Penicillium sp. esteja relacionada a grãos assintomáticos, Pinto (2001) afirma que este fungo normalmente não está associado aos grãos de milho imediatamente após a colheita, mas que pode ser um agente "apodrecedor" de espigas. Além disso, grãos assintomáticos podem ser selecionados,

Tabela 4. Precentagem de incidência de fungos associados a grãos de milho (Zea mays) assintomáticos (GAS) e ardidos (GAR) nos três ensaios realizados, um no município de Luís Eduardo Magalhães, BA, e dois em Sete Lagoas, MG, nas safras 2010/2011 e 2011/2012(1).

\begin{tabular}{|c|c|c|c|c|c|c|}
\hline \multirow[t]{2}{*}{ Fungo } & \multicolumn{2}{|c|}{ Luís Eduardo Magalhães, safra 2010/20111 } & \multicolumn{2}{|c|}{ Sete Lagoas, safra 2010/2011 } & \multicolumn{2}{|c|}{ Sete Lagoas, safra 2011/2012 } \\
\hline & GAS & GAR & GAS & GAR & GAS & GAR \\
\hline Fusarium spp. & $85,02 \mathrm{a}$ & $92,46 b$ & $38,87 \mathrm{a}$ & $73,51 b$ & $54,60 \mathrm{a}$ & $84,73 b$ \\
\hline Penicillium spp. & $29,11 b$ & $12,27 \mathrm{a}$ & $10,09 b$ & $4,43 a$ & $9,73 b$ & $3,56 a$ \\
\hline Stenocarpella spp. & $0,01 \mathrm{a}$ & $3,73 b$ & $0,12 \mathrm{a}$ & $17,04 \mathrm{~b}$ & $0,16 \mathrm{a}$ & $13,06 \mathrm{~b}$ \\
\hline
\end{tabular}

${ }^{(1)}$ Médias seguidas de letras iguais, nas linhas, não diferem pelo teste $\mathrm{F}$, a $5 \%$ de probabilidade. 
por não apresentarem sintomas, e transportados até o armazém, onde o fungo pode causar danos severos.

A elevada incidência do patógeno Penicillium sp. em grãos de milho é um fator preocupante, pois tratase de um organismo produtor de uma micotoxina, a ocratoxina, que está associada ao câncer em seres humanos e animais (Machinski et al., 2001). Apesar de também produzir essa micotoxina, Aspergillus sp. apresentou incidência pouco relevante nos ensaios. A baixa incidência desse fungo, imediatamente após a colheita, também foi relatada em outros trabalhos (Stefanello et al., 2012); entretanto, sua incidência pode variar muito de acordo com o genótipo ou as condições climáticas (Ramos et al., 2010a).

Quanto aos teores de fumonisinas totais encontrados nos dois primeiros ensaios, não houve diferença para nenhum dos fatores avaliados. Os teores médios de fumonisinas totais observados nesses dois ensaios foram de 7,99 e 0,94 $\mu \mathrm{g} \mathrm{g}^{-1}$, respectivamente. Para o ensaio conduzido em Sete Lagoas, na safra 2011/2012, os híbridos DKB 390, DKB 550 e 30F35 apresentaram os menores teores de fumonisinas, enquanto o híbrido DKB 330 mostrou-se mais suscetível quanto à acumulação de fumonisinas totais, tendo apresentado média de 3,4 $\mu \mathrm{g} \mathrm{g}^{-1}$ (Tabela 2).

Portanto, os fungicidas avaliados, independentemente do número e da época de aplicações, não foram eficientes em reduzir os teores de fumonisinas totais, tanto nos ensaios que apresentaram altos teores quanto nos que apresentaram baixos teores ou que foram realizados em diferentes híbridos de milho. Cabe ressaltar que, até o presente, não há conhecimento de trabalhos que estudem o efeito de fungicidas sobre os teores de fumonisinas em experimentos em campo.

Tabela 5. Rendimento de grãos (peso de mil grãos) para os ensaios conduzidos em Luís Eduardo Magalhães (LEM), BA, e em Sete Lagoas, MG, na safra 2010/2011(1).

\begin{tabular}{lcc}
\hline Fungicida & \multicolumn{2}{c}{ Rendimento de grãos $(\mathrm{g})$} \\
\cline { 2 - 3 } & LEM & Sete Lagoas \\
\hline Testemunha (sem aplicação) & $273,85 \mathrm{~b}$ & $315,09 \mathrm{a}$ \\
Picoxistrobina + Ciproconazol & $302,01 \mathrm{a}$ & - \\
Trifloxistrobina + Tebuconazole & $304,47 \mathrm{a}$ & $293,68 \mathrm{a}$ \\
Piraclostrobina + Epoxiconazole & $309,72 \mathrm{a}$ & $320,12 \mathrm{a}$ \\
Azoxistrobina + Ciproconazol & $322,61 \mathrm{a}$ & $314,40 \mathrm{a}$ \\
\hline
\end{tabular}

${ }^{(1)}$ Médias seguidas de letra iguais, nas colunas, não diferem pelo teste de Tukey, a 5\% de probabilidade. -, não avaliado.
Foram observadas diferenças no rendimento de grãos para os fatores híbridos, fungicidas e número de aplicações, nos ensaios em Luís Eduardo Magalhães e em Sete Lagoas, na safra 2011/2012, mas não na safra 2010/2011 (Tabelas 2 e 5); contudo, não houve diferença quanto à interação entre esses fatores.

Para o ensaio em Luís Eduardo Magalhães, a aplicação de fungicidas foi eficiente. Com relação ao número de aplicações, foi detectada diferença entre zero, uma e duas aplicações, com valores médios de rendimento de grãos de 273,9, 292,3 e 312,8 g, respectivamente.

No ensaio em Sete Lagoas, na safra 2011/2012, os híbridos DKB 550 e DKB 390 apresentaram os maiores rendimentos de grãos, enquanto os híbridos 30F35 e DKB 330 apresentaram os menores (Tabela 3). Para esse mesmo ensaio, o número de aplicações de tiofanato metílico influenciou o rendimento de grãos, em que duas aplicações do produto proporcionaram maior rendimento.

Desse modo, as aplicações de fungicidas colaboraram para um maior rendimento de grãos em comparação à testemunha, provavelmente em razão da elevada severidade da ferrugem polissora (Puccinia polysora) observada em campo nos ensaios em Luís Eduardo Magalhães e em Sete Lagoas, na safra 2011/2012. Além disso, a aplicação dos fungicidas promoveu redução na severidade da ferrugem, com consequente aumento no peso médio de grãos das parcelas tratadas. Devese destacar que, como não houve ocorrência severa de doenças foliares ao longo do ciclo da cultura no ensaio em Sete Lagoas, na safra 2010/2011, não foi possível observar efeito positivo da aplicação de fungicidas no aumento do rendimento de grãos.

Esses resultados são indicativos de que o incremento na produção da cultura do milho, decorrente da aplicação de fungicidas, ocorreu de forma mais consistente em situações de elevada pressão de doenças foliares. Costa et al. (2012) constataram que as aplicações de fungicidas, pertencentes ao grupo das estrobilurinas, apresentaram inconsistência em condições de baixa severidade de doenças. Conforme esses autores, rendimentos positivos e benefício econômico ocorrem quando as aplicações de fungicidas são realizadas em condições de elevada pressão de doença, como verificado no presente trabalho.

A avaliação de fungicidas foliares em milho, com vistas à redução dos teores de fumonisinas totais nos 
grãos, mostrou a ineficiência dos produtos testados, em diferentes épocas e números de aplicações. Vale ressaltar, entretanto, que não foram avaliados todos os fungicidas registrados para a cultura do milho no Brasil (Brasil, 2015), nem novas metodologias de aplicação desses fungicidas, não sendo possível extrapolar os resultados obtidos para todos os produtos ou metodologias de aplicação.

\section{Conclusão}

A incidência de grãos ardidos e de fungos fitopatogênicos, assim como os teores de fumonisinas totais em grãos de milho (Zea mays), não é influenciada pela aplicação de fungicidas, independentemente do número de aplicações e do ciclo da cultura.

\section{Agradecimentos}

Ao Conselho Nacional de Desenvolvimento Científico e Tecnológico $(\mathrm{CNPq})$ e à Fundação de Amparo à Pesquisa do Estado de Minas Gerais (Fapemig), pelo apoio financeiro.

\section{Referências}

AGÊNCIA NACIONAL DE VIGILÂNCIA SANITÁRIA. Resolução RDC no 7, de 18 de fevereiro de 2011. Dispõe sobre limites máximos tolerados (LMT) para micotoxinas em alimentos. Diário Oficial [da] República Federativa do Brasil, 9 mar. 2011. Seção 1, p.66-67.

AGRIANUAL 2015: anuário da agricultura brasileira. 20.ed. São Paulo: FNP, 2015.

BRASIL. Ministério da Agricultura, Pecuária e Abastecimento Agrofit: sistema de agrotóxicos fitossanitários. Disponível em: $<$ http://extranet.agricultura.gov.br/agrofit_cons/principal_agrofit_ cons $>$. Acesso em: 15 dez. 2015.

BRASIL. Ministério da Agricultura, Pecuária e Abastecimento. Regras para análise de sementes. Brasília: Secretaria de Defesa Agropecuária, 2009. 395p.

BRITO, A.H.; PEREIRA, J.L. de A.R.; VON PINHO, R.G.; BALESTRE, M. Controle químico de doenças foliares e grãos ardidos em milho (Zea mays L.). Revista Brasileira de Milho e Sorgo, v.11, p.49-59, 2012. DOI: 10.18512/1980-6477/rbms. v11n1p49-59.

CASA, R.T.; REIS, E.M.; ZAMBOLIM, L. Doenças do milho causadas por fungos do gênero Stenocarpella. Fitopatologia Brasileira, v.31, p.427-439, 2006. DOI: 10.1590/ S0100-41582006000500001.

COSTA, R.V. da; COTA, L.V.; SILVA, D.D. da; MEIRELLES, W.F.; LANZA, F.E. Viabilidade técnica e econômica da aplicação de estrobilurinas em milho. Tropical Plant Pathology, v.37, p.246-254, 2012. DOI: 10.1590/S1982-56762012000400003.

DE CURTIS, F.; DE CICCO, V.; HAIDUKOWSKI, M.; PASCALE, M.; SOMMA, S.; MORETTI, A. Effects of agrochemical treatments on the occurrence of Fusarium ear rot and fumonisin contamination of maize in Southern Italy. Field Crops Research, v.123, p.161-169, 2011. DOI: 10.1016/j.fcr.2011.05.012.

DUARTE, R.P.; JULIATTI, F.C.; LUCAS, B.V.; FREITAS, P.T. de. Comportamento de diferentes genótipos de milho com aplicação foliar de fungicidas quanto à incidência de fungos causadores de grãos ardidos. Bioscience Journal, v.25, p.112-122, 2009.

GELDERBLOM, W.C.A.; JASKIEWICZ, K.; MARASAS, W.F.O; THIEL, P.G.; HORAK, R.M.; VLEGGAAR, R.; KRIEK, N.P.J. Fumonisins-novel mycotoxins with cancer-promoting activity produced by Fusarium moniliforme. Applied and Environmental Microbiology, v.54, p.1806-1811, 1988.

JACKSON, L; JABLONSKI, J. Fumonisins. In: MAGAN, N.; OLSEN, M. (Ed.). Mycotoxins in food: detection and control. Abington: Woodhead Publishing Ltd; CRC Press LLC, 2004. p.367-405.

JULIATTI, F.C.; ZUZA, J.L.M.F.; SOUZA, P.P. de; POLIZEL, A.C. Efeito do genótipo de milho e da aplicação foliar de fungicidas na incidência de grãos ardidos. Bioscience Journal, v.23, p.34-41, 2007.

KIMATI, H. Controle químico. In: AMORIM, L.; REZENDE, J.A.M.; BERGAMIN FILHO, A. (Ed.). Manual de fitopatologia: princípios e conceitos. 4.ed. São Paulo: Agronômica Ceres, 2011. v.1, 704p.

MACHADO, J. da C. Patologia de sementes: fundamentos e aplicações. Brasília: MEC/FAEPE, 1988. 107p.

MACHINSKI JR, M.; VALENTE SOARES, L.M.; SAWAZAKI, E.; BOLONHEZI, D.; CASTRO, S.L.; BORTOLLETO, N. Aflatoxins, ochratoxin A and zearalenone in Brazilian corn cultivars. Journal of the Science of Food and Agriculture, v.81, p.1001-1007, 2001. DOI: 10.1002/jsfa.882.

MAZZONI, E.; SCANDOLARA, A.; GIORNI, P.; PIETRI, A.; BATTILANI, P. Field control of Fusarium ear rot, Ostrinia nubilalis (Hübner), and fumonisins in maize kernels. Pest Management Science, v.67, p.458-465, 2011. DOI: 10.1002/ps.2084.

MUNKVOLD, G.P.; DESJARDINS, A.E. Fumonisins in maize: can we reduce their occurrence? Plant Disease, v.81, p.556-565, 1997. DOI: 10.1094/PDIS.1997.81.6.556.

OLIVEIRA, E. de; FERNANDES, F.T.; CASELA, C.R.; PINTO, N.F.J. de A.; FERREIRA, A. da S. Diagnose e controle de doenças na cultura do milho. In: GALVÃO, J.C.C.; MIRANDA, G.V. (Ed.). Tecnologias de produção do milho. Viçosa: Universidade Federal de Viçosa, 2004. p.227-267.

PEREIRA, O.A.P.; CARVALHO, R.V.; CAMARGO, L.E.A. Doenças do milho. In: KIMATI, H.; AMORIM, L.; REZENDE, J.A.M.; BERGAMIN FILHO, A.; CAMARGO, L.E.A. (Ed.). Manual de fitopatologia: doenças das plantas cultivadas. 4.ed. São Paulo: Agronômica Ceres, 2005. v.2, 666p. 
PINTO, N.F.J. de A. Grãos ardidos em milho. Sete Lagoas: Embrapa Milho e Sorgo, 2005. 5p. (Embrapa Milho e Sorgo. Circular técnica, 66).

PINTO, N.F.J. de A. Qualidade sanitária de grãos de milho. Sete Lagoas: Embrapa Milho e Sorgo, 2001. 4p. (Embrapa Milho e Sorgo. Comunicado técnico, 30).

RAMOS, A.T.M.; MORAES, M.H.D. de; CARVALHO, R.V. de; CAMARGO, L.E.A. Levantamento da micoflora presente em grãos ardidos e sementes de milho. Summa Phytopathologica, v.36, p.257-259, 2010a. DOI: 10.1590/S0100-54052010000300015.

RAMOS, C.M.; MARTINEZ, E.M.; CARRASCO, A.C.; PUENTE, J.H.L.; QUEZADA, F.; PEREZ, J.T.; OSWALD, I.P.; ELVIRA,
S.M. Experimental trial of the effect of fumonisin $B_{1}$ and the PRRS virus in swine. Journal of Animal and Veterinary Advances, v.9, p.1301-1310, 2010b. DOI: 10.3923/javaa.2010.1301.1310.

SMALL, I.M.; FLETT, B.C.; MARASAS, W.F.O.; MCLEOD, A.; VILJOEN, A. Use of resistance elicitors to reduce Fusarium ear rot and fumonisin accumulation in maize. Crop Protection, v.41, p.10-16, 2012. DOI: 10.1016/j.cropro.2012.05.016.

STEFANELLO, J.; BACHI, L.M.A.; GAVASSONI, W.L.; HIRATA, L.M.; PONTIM, B.C.A. Incidência de fungos em grãos de milho em função de diferentes épocas de aplicação foliar de fungicida. Pesquisa Agropecuária Tropical, v.42, p.476-481, 2012. DOI: 10.1590/S1983-40632012000400014.

Recebido em 2 de setembro de 2014 e aprovado em 26 de janeiro de 2016 